\title{
Lesions of Orbitofrontal Cortex and Basolateral Amygdala Complex Disrupt Acquisition of Odor-Guided Discriminations and Reversals
}

\author{
Geoffrey Schoenbaum, ${ }^{1}$ Barry Setlow, Summer L. Nugent, Michael P. Saddoris, and \\ Michela Gallagher \\ Department of Psychological and Brain Sciences, Johns Hopkins University, Baltimore, Maryland 21218, USA
}

\begin{abstract}
Recent work indicates that both orbitofrontal cortex (OFC) and the basolateral complex of the amygdala (ABL) are involved in processes by which cues are associated with predicted outcomes. To examine the respective roles of these structures in discrimination learning, rats with bilateral sham or neurotoxic lesions of either OFC or ABL were trained on a series of four 2-odor discrimination problems in a thirst-motivated go, no-go task. After acquisition of the series of odor problems, the rats were trained on serial reversals of the final odor problem. Performance on each problem was assessed by monitoring accuracy of choice behavior, and also by measuring latency to respond for fluid outcomes after odor sampling. During discrimination learning, rats in both lesioned groups had similar deficits, failing to show normal changes in response latency during learning, while at the same time exhibiting normal choice behavior relative to controls. Choice behavior was affected only during the reversal phase of training, in which OFC and ABL lesions produced distinctive deficits. Rats with ABL lesions were impaired on the first reversal (S1-/S2+), but were unimpaired at acquiring a reversal back to the original odor-outcome contigencies $(\mathrm{S} 1+/ \mathrm{S} 2-)$, whereas rats with $\mathrm{OFC}$ lesions were impaired on both types of reversals. These findings suggest that OFC and ABL serve partially overlapping roles in the use of incentive information that supports normal discrimination performance.
\end{abstract}

The amygdala complex has long been implicated in emotional processes (Brown and Schafer 1888; Kluver and Bucy 1939). Weiskrantz (1956) proposed a role for the amygdala in forming associations between otherwise neutral cues and events with natural rewarding or aversive properties, a function now known to involve the basolateral complex (ABL, consisting of the lateral, basal, and accessory basal nuclei) (Davis 1992; LeDoux 1996; Everitt et al. 2000). The $\mathrm{ABL}$ has strong reciprocal connections with the orbitofrontal cortex (OFC) (Krettek and Price 1977; Kita and Kitai 1990; Carmichael and Price 1995; Shi and Cassell 1998; Ongur and Price 2000), which has also been implicated in mediating affective processes (Harlow 1868). Damage to either ABL or OFC has often been noted to produce similar behavioral impairments (e.g., Hatfield et al. 1996; Bechara et al. 1997, 1999; Gallagher et al. 1999).

Evidence from studies of primates and non-primates now suggests that OFC and ABL together form a system to mediate goal-directed behavior through an associative function in which cues are linked to predicted outcomes. Human subjects with either orbitofrontal or amygdala damage

${ }^{1}$ Corresponding author.

E-MAIL schoenbg@jhu.edu; FAX (410) 516-6205.

Article and publication are at http://www.learnmem.org/cgi/doi/ $10.1101 / \mathrm{lm} .55203$. are impaired in developing goal-directed behavior in a gambling task, an impairment that appears to reflect abnormal associations between cues and the value of likely outcomes (Bechara et al. 1997, 1999). Information representing the incentive value of expected outcomes is represented by neural activity in these structures in monkeys and rodents (Schoenbaum et al. 1998, 1999; Tremblay and Schultz 1999), and experimentally induced lesions of OFC and ABL in these species eliminate the ability of animals to appropriately guide responses on the basis of changes in the value of the predicted outcome (Hatfield et al. 1996; Malkova et al. 1997; Gallagher et al. 1999; Baxter et al. 2000; Izquierdo and Murray 2000).

Despite many broad similarities, distinctive results have also been reported in studies of OFC and ABL. Notably, the literature generally indicates no discernible impairment in simple discrimination learning after ABL damage, whereas deficits in acquisition after OFC damage are sometimes reported. In addition, OFC damage invariably impairs reversal learning in such tasks. Electrophysiological data from our laboratory have also shown differences in the information represented by neurons in $\mathrm{OFC}$ and $\mathrm{ABL}$ during acquisition and reversal learning in a go, no-go odor discrimination task (Schoenbaum et al. 1998, 1999, 2000).

To examine further the respective contributions of OFC and ABL to associative learning, we evaluated the effects of bilateral lesions of each structure on performance in

LEARNING \& MEMORY 10:129-140 @ 2003 by Cold Spring Harbor Laboratory Press ISSN1072-0502/03 \$5.00

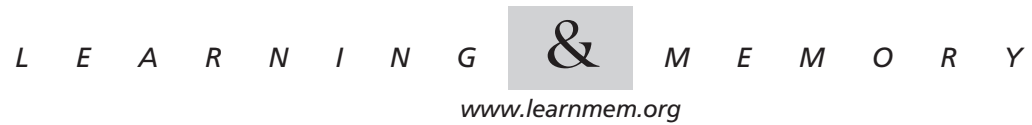


the same behavioral task used in our previous electrophysiological recording experiments. In this task, thirsty rats learned four odor problems in which they had to discriminate between two odors to obtain an appetitive sucrose solution and to avoid an aversive quinine solution (Fig. 1). Two measures of behavioral performance were used as follows: (1) choice behavior measured as the accuracy of go and no-go responses, and (2) latency to respond at the fluid well following odor sampling, which may reflect the acquired value of the odor cues (Holland and Straub 1979; Sage and Knowlton 2000; Watanabe et al. 2001). After discrimination learning was evaluated in this way, we also examined the effects of the lesions on serial reversals of the final odor problem in the series.

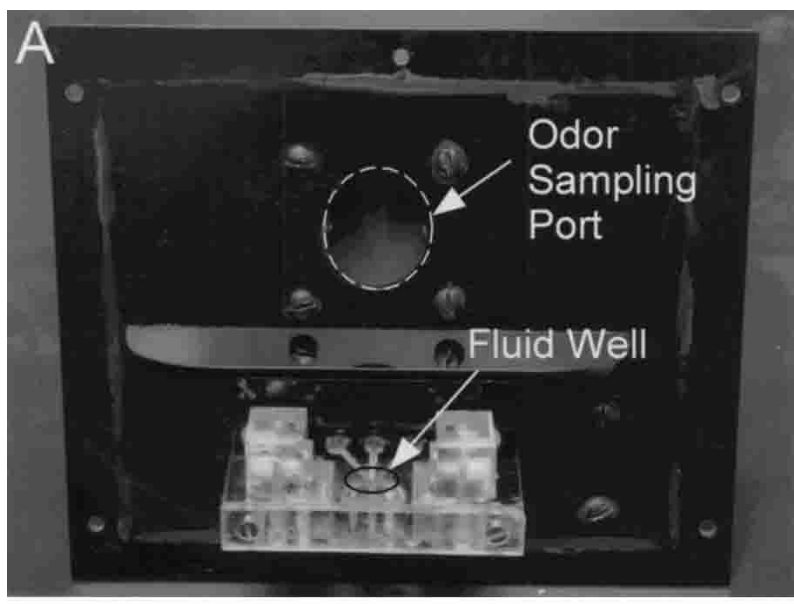

B

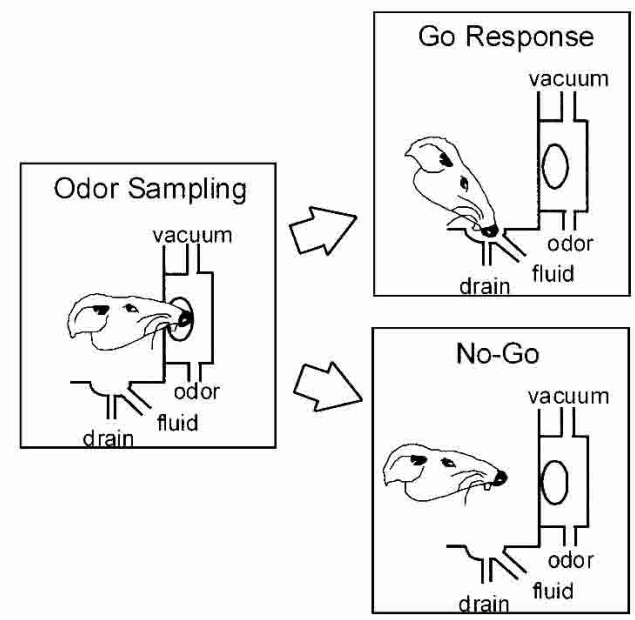

Figure 1 Illustration of training apparatus and behaviors in the task. (A) Photograph of the polycarbonate panel removed from the operant chamber to show the odor sampling port (white circle) and the fluid delivery well (black circle). (B) Schematic drawings illustrating the sequence of behaviors in the go, no-go olfactory discrimination task using the apparatus in $A$.

\section{RESULTS}

\section{Orbitofrontal Cortex Lesions}

\section{Histology of Neurotoxic OFC Lesions}

Of the 16 rats that underwent surgery to create bilateral OFC lesions, data were obtained from 8 rats judged to have acceptable bilateral lesions of OFC. As illustrated in Figure 2 , these rats had a marked loss of neurons in OFC, encompassing medial, ventrolateral, and lateral orbital regions and both dorsal and ventral agranular insular cortex. This target region was designed to include areas on the dorsal bank of the rhinal sulcus that receive olfactory input from piriform cortex (Cinelli et al. 1985; Price et al. 1991) and more laterally located insular regions that have direct interactions with ABL (Krettek and Price 1977; Kita and Kitai 1990; Shi and Cassell 1998). The target region did not extend into gustatory regions located in agranular insular cortex posterior to the genu of the corpus callosum (Saper 1982; Kosar et al. 1986; Krushel and Van Der Kooy 1988). On average, lesions encompassed $78 \%$ of OFC bilaterally, ranging from $70 \%-90 \%$. Rats were excluded if damage to OFC was $<50 \%$ in either hemisphere, or if there was extensive bilateral damage to structures outside of the target region. There was no discernable damage in any of the eight sham-lesioned control rats.

\section{Acquisition of New Discriminations in Rats With OFC Lesions}

The acquisition of each odor discrimination problem by the rats in the OFC lesioned and control groups is shown in Figure 3. All rats, irrespective of lesion condition, achieved criterion on each of the four discrimination problems. A 2-factor ANOVA (lesion X odor problem) revealed no effect of lesion condition on acquisition, nor was there any interaction between lesion and odor problem. Thus, OFC lesions did not impair the rats' ability to acquire odor discriminations at a rate comparable with that of control animals. As expected, there was a significant main effect of odor problem $\left(\mathrm{F}_{3,42}=130, P<0.01\right)$, such that acquisition on the first shaping problem (D1) required more trials than on subsequent nonshaping problems (D2-D4). When the first problem was excluded, there were no significant effects or interactions.

Subsequent analyses focused on performance during acquisition of these three odor problems (D2-D4). The performance of lesioned and control rats was similar across these problems. This similarity in the performance of the two groups was evident when the pre-criterion trials were divided into early and late blocks as described in the Methods section for the purpose of response latency analysis. The number of trials in each block did not differ significantly between groups, and rats also performed at a similar level of accuracy across the different trial blocks. OFC-le-

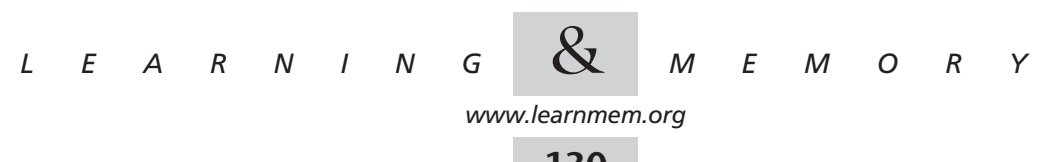



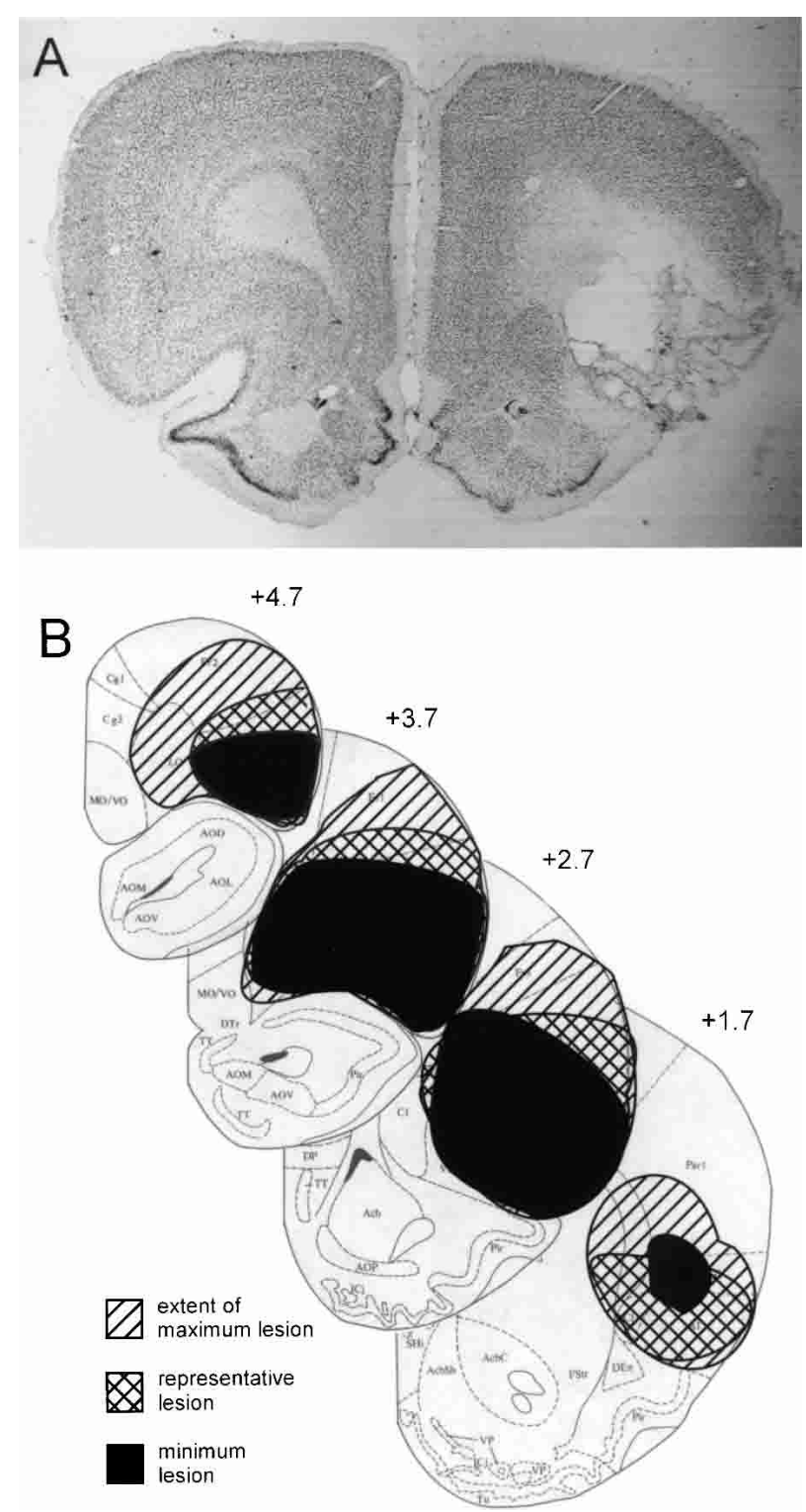

Figure 2 Photomicrograph and drawings showing a reconstruction of the region of damage in OFC in lesioned subjects. (A) Photomicrograph of coronal sections taken through the orbitofrontal region in a control (left) and a lesioned (right) rat. Note the loss of cells and consolidation in the orbitofrontal area, accompanied by gliosis at the borders of the lesion. (B) Drawings depict the largest (diagonal hatched areas) and smallest (black areas) lesions in each section from animals used in the experiment. A representative lesion is also shown (cross-hatched areas). Plates are adapted from the atlas of Swanson (1992).

sioned rats performed at $62 \%$ correct and $74 \%$ correct in the early and late blocks, respectively, and at $92 \%$ in the postcriterion block, whereas controls performed at $61 \%$ correct in the early block, $72 \%$ correct in the late block, and $91 \%$ in the post-criterion block.

\section{Response Latency During Acquisition of New Discriminations in Rats With OFC Lesions}

Prior observations in our laboratory (Schoenbaum et al. 2000) indicate that rats normally develop a difference in latency to enter the fluid well after sampling odors that signal positive versus negative contingencies. Responses are made more rapidly after sampling a positive odor, whereas responses are made more slowly after sampling a negative odor over the course of precriterion training. This behavioral phenomenon is evident in the results presented for the control group in Figure 4, in which a latency difference emerged during precriterion trials. In contrast, rats with OFC lesions failed to develop this difference in response latency. A 3-factor ANOVA (lesion X odor problem X latency difference) revealed a significant effect of lesion on latency difference $\left(\mathrm{F}_{1,14}=9.97, P<0.01\right)$. There was no impact of odor problem on the lesion effect, so this factor was collapsed in evaluating the interaction between lesion and latency difference. Subsequent contrast testing revealed that the difference in response latency (negative - positive) for control rats increased significantly from $-26 \mathrm{msec}$ during the early phase $(558-532 \mathrm{msec})$ to $233 \mathrm{msec}$ during the late phase $(621-388 \mathrm{msec})$, whereas OFC-lesioned rats exhibited a nonsignificant change from $-33 \mathrm{msec}(610-577$ $\mathrm{msec})$ to $10 \mathrm{msec}(490-480 \mathrm{msec})$.

It is important to note that the development of a latency difference in intact rats was due to both slower responses on negative trials $\left(\mathrm{F}_{1,14}=29.7, P<0.01\right)$ and faster responses on positive trials $\left(\mathrm{F}_{1,14}=6.66, P<0.05\right)$ after the early phase of training. OFC-lesioned rats exhibited more rapid responses on both positive $\left(\mathrm{F}_{1,14}=25.4, P<0.01\right)$ and negative trials $\left(\mathrm{F}_{1,14}=10.04, P<0.01\right)$; however, there were no differences in their response latency between positive and negative trials in any of these phases. In addition, lesioned rats exhibited significantly slower responses than intact rats on positive trials in the late and post-criterion phases $\left(\mathrm{F}_{1,14}=5.14, P<0.05\right)$, but not in the early phase. These data indicate that OFC-lesioned rats were impaired both at inhibiting responding on negative trials and at facilitating responding on positive trials relative to intact rats. This point is particularly important given the history of attributing the function of response inhibition to OFC.

\section{Performance During Serial Reversals in Rats With OFC Lesions}

The performance of control and OFC-lesioned rats across two serial reversals is shown in Figure 5. Reversal training used the final odor discrimination problem (D4) from the first training phase. Rats were required to demonstrate retention of the original contingencies $(\mathrm{S} 1+/ \mathrm{S} 2-)$ by meeting the behavioral criterion of $18 / 20$ correct, and then acquire a reversal of those contingencies (S1-/S2+) by meeting the same criterion. Subsequently, the rats were required to demonstrate retention of the altered contingencies (S1-/S2+),

\section{$\begin{array}{lllllllllllllll}L & E & A & R & N & I & N & G & \mathbf{Z} & M & E & M & O & R & Y \\ \text { www.learnmem.org } & & & \end{array}$}




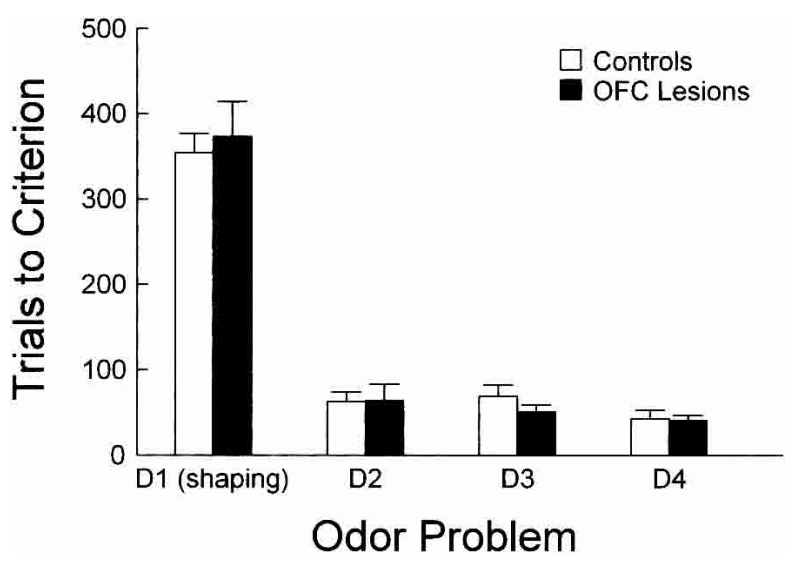

Figure 3 Acquisition of successive odor discrimination problems by OFC lesioned (black bars) and control (white bars) rats. Rate of acquisition of each odor discrimination problem (D1, D2, D3, D4) is represented as the trials it took for each rat to meet a criterion of 18 correct responses in a moving block of 20 trials. There was no effect of lesion on acquisition of any of the individual odor discriminations or on the improvement observed across successive problems.

then acquire a reversal back to the original contingencies $(\mathrm{S} 1+/ \mathrm{S} 2-)$. As described in the Methods section, rats were required to be at $80 \%$ performance prior to reversal (there were no differences between sham and lesioned rats in the amount of training necessary to meet this requirement).

As shown in Figure 5, rats with OFC lesions were impaired on the initial reversal ( $\mathrm{S} 1-/ \mathrm{S} 2+)$. After showing good retention of these altered contingencies, OFC-lesioned rats were also impaired in acquiring a second reversal back to the original contingencies $(\mathrm{S} 1+/ \mathrm{S} 2-)$. In agreement with this description, a 3-factor ANOVA (lesion X contingency $\mathrm{X}$ reversal) showed significant main effects of lesion $\left(\mathrm{F}_{1,14}=7.5, P<0.05\right)$ and reversal $\left(\mathrm{F}_{1,14}=62.4, P<0.01\right)$, and a significant interaction between lesion and reversal $\left(\mathrm{F}_{1,14}=6.0, P<0.05\right)$. There was no main effect or any interactions involving contingency. Thus, rats with OFC lesions were impaired in acquiring reversals of the odor problem, irrespective of whether the reversal involved the original or altered contingencies.

This reversal impairment did not appear to be due to perseveration on the old contingencies after reversal. Examination of performance on the reversal days revealed that OFC-lesioned and control rats both reached chance performance of $50 \%$ after reversal at similar rates (Fig. 5, gray areas). A 2-factor ANOVA (lesion X reversal session) comparing the trials required to reach $50 \%$ performance after reversal showed no significant main effect or interaction with lesion. There was a significant main effect of reversal session $\left(\mathrm{F}_{1,14}=21.04, P<0.01\right)$, indicating that both lesioned and control rats required fewer trials to reach 50\% performance on the second reversal than on the first one.

\section{Basolateral Amygdala Lesions}

Histology of Neurotoxic ABL Lesions

Of the 14 rats that underwent surgery to create bilateral ABL lesions, data were obtained from nine rats judged to have acceptable bilateral lesions of ABL. As illustrated in Figure 6, lesioned areas were clearly distinguished by an absence of neurons and extensive gliosis in the area of ABL, as well as by the presence of intact neurons at the lesion borders. The lesions generally encompassed the entire anterior-posterior extent of $\mathrm{ABL}$, and included the lateral, basal, and accessory basal nuclei. Damage that extended beyond the boundaries of $\mathrm{ABL}$ included occasional loss of neurons in the adjacent endopiriform nucleus and piriform cortex, as well as minor damage to the overlying caudate-putamen along the injection needle track. In addition, there was minor damage to the lateral aspect of the central nucleus of the amygdala. In no case, was collateral damage to any of these structures extensive, and typically it was unilateral. There was no discernable damage in any of the 10 shamlesioned control rats.

\section{Acquisition of New Discriminations in Rats With ABL Lesions}

The acquisition of each odor discrimination problem by the rats in the ABL-lesioned and control groups is shown in Figure 7. All rats, irrespective of lesion condition, achieved criterion on each of the four discrimination problems. A 2-factor ANOVA (lesion X odor problem) revealed no effect of lesion condition on acquisition, nor was there any interaction between lesion condition and odor problem. Thus, ABL lesions did not impair the rats' ability to acquire odor

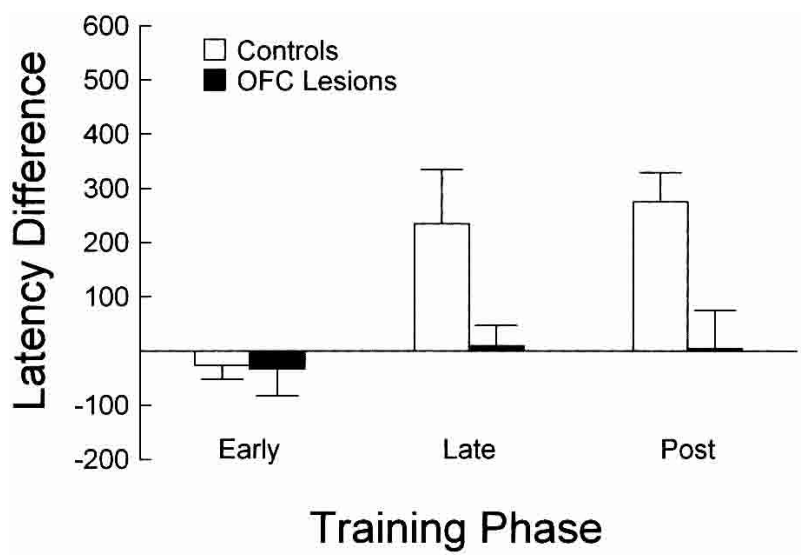

Figure 4 Difference in latency (milliseconds) to respond at the fluid well after the end of odor sampling for OFC lesioned (black bars) and control (white bars) rats. Difference was calculated as the average response latency on negative minus positive trials within each phase, averaged for the second (D2), third (D3), and fourth (D4) discrimination problems. No-go trials, in which the rat made no response for $3000 \mathrm{msec}$, were excluded from the analysis. OFClesioned rats failed to develop the learning-related latency difference exhibited by control rats.

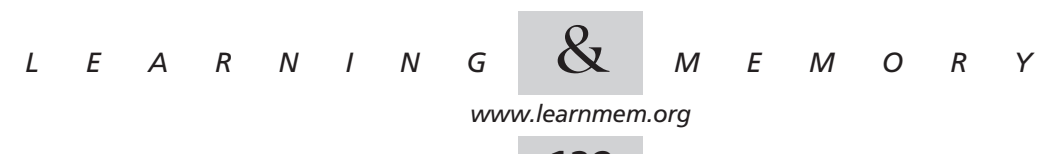




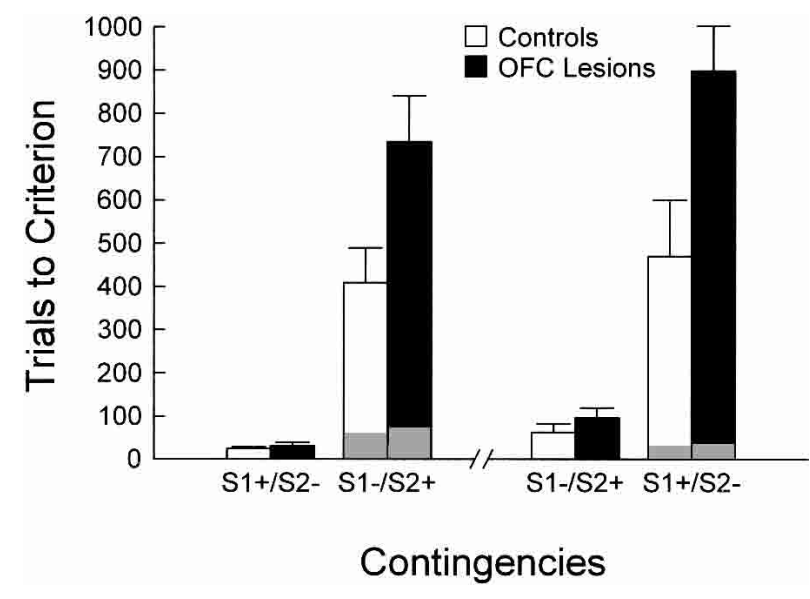

Figure 5 Choice performance across serial reversals of the final odor discrimination problem (D4) by OFC-lesioned (black bars) and control (white bars) rats. Performance is shown for both the retention and reversal phases of training, represented as the trials required for each rat to meet a criterion of 18 correct responses in a moving block of 20 trials. Gray areas on reversal days indicate the trials required to reach $50 \%$ performance as a measure of perseveration on the old contingencies. OFC-lesioned rats were impaired at acquiring reversals, irrespective of whether the reversed odor discrimination problem was composed of new contingencies (S1-/S2+) or was a return to the original contingencies (S1+/S2-). There was no effect of lesion on the tendency to perseverate on reversal days.

discriminations at a rate comparable with that of control animals. As expected, there was a significant main effect of odor problem $\left(\mathrm{F}_{3,51}=64.2, P<0.01\right)$, such that acquisition on the first shaping problem (D1) required more trials than on subsequent nonshaping problems (D2-D4). When the first problem was excluded, there were no significant effects or interactions.

Subsequent analyses focused on behavior during acquisition of these three odor problems (D2-D4). The performance of lesioned and control rats was similar across these problems. The similarity in the performance of the two groups was evident when the pre-criterion trials were divided into early and late blocks as described in the Methods section for the purpose of response latency analysis. The number of trials in each block did not differ significantly between groups, and rats also performed at a similar level of accuracy across the different trial blocks. ABL-lesioned rats performed at $64 \%$ correct and $76 \%$ correct in the early and late blocks, respectively, and at $88 \%$ in the post-criterion block, whereas controls performed at $63 \%$ correct in the early block, $75 \%$ correct in the late block, and $87 \%$ in the post-criterion block.

\section{Response Latency During Acquisition of New Discriminations in Rats With ABL Lesions}

As in the first experiment, we examined the latency to enter the fluid well after odor sampling. Again, control rats devel- oped a difference in response latency on positive and negative trials. This phenomenon is evident in the results presented for the control group in Figure 8. In contrast, rats with ABL lesions failed to develop this difference in response latency. A 3-factor ANOVA (lesion X odor problem X latency difference) revealed a significant effect of lesion on latency difference $\left(\mathrm{F}_{2,34}=9.8, P<0.01\right)$. There was no impact of odor problem on the effect of lesion, so this factor was collapsed in evaluating the interaction between lesion and latency difference. Contrast testing revealed that the difference in response latency (negative - positive) for control rats increased significantly from $-78 \mathrm{msec}$ during the early phase $(565-643 \mathrm{msec})$ to $300 \mathrm{msec}$ during the late phase (707 - $407 \mathrm{msec})$, whereas ABL-lesioned rats exhibited a nonsignificant change from $36 \mathrm{msec}$ (581-545 msec) to $116 \mathrm{msec}(495-379 \mathrm{msec})$.

\section{Performance During Serial Reversals in Rats With ABL Lesions}

The performance of control and ABL-lesioned rats across two serial reversals is shown in Figure 9. Reversal training used the final odor discrimination problem (D4) from the first training phase. Rats were required to demonstrate retention of the original contingencies $(\mathrm{S} 1+/ \mathrm{S} 2-)$ by meeting the behavioral criterion of $18 / 20$ correct, and then acquire a reversal of those contingencies $(\mathrm{S} 1-/ \mathrm{S} 2+)$ by meeting the same criterion. Subsequently, the rats were required to demonstrate retention of the altered contingencies (S1-/S2+), then acquire a reversal back to the original contingencies $(\mathrm{S} 1+/ \mathrm{S} 2-)$. As described in the Methods section, rats also had to be at $80 \%$ performance prior to reversal (there were no differences between sham and lesioned rats in the amount of training necessary to meet this requirement).

As shown in Figure 9, rats with ABL lesions performed worse than controls in acquiring the initial reversal (S1-/S2+). In contrast to the effect of OFC lesions in this same paradigm, however, rats with $\mathrm{ABL}$ lesions also performed more poorly than controls in the subsequent test for retention of this reversal, but then showed no difficulty compared with controls in acquiring the second reversal back to the original contingencies ( $\mathrm{S} 1+/ \mathrm{S} 2-)$. In agreement with this description, a 3-factor ANOVA (lesion X contingency $\mathrm{X}$ reversal) showed a significant main effect of reversal $\left(\mathrm{F}_{1,15}=78.4, P<0.01\right)$ and a significant interaction between lesion and contingency $\left(\mathrm{F}_{1,15}=4.8, P<0.05\right)$. There was no interaction between lesion and reversal, nor was there a main effect of lesion. Thus, rats with ABL lesions were impaired in the reversal phase, but the impairment reflected difficulty acquiring and retaining the altered contingencies of the discrimination problem rather than a problem with reversal learning per se. As was the case with OFC-lesioned rats, ABL-lesioned rats did not differ from controls in the number of trials required to reach $50 \%$ performance on either reversal (Fig. 9). A 2-factor ANOVA (lesion

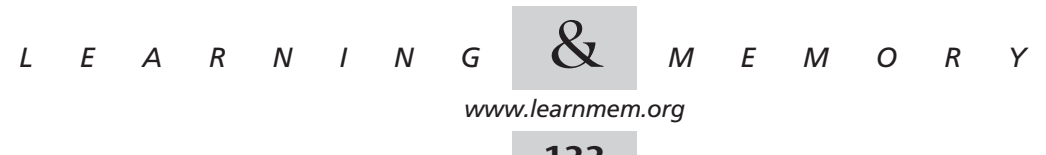



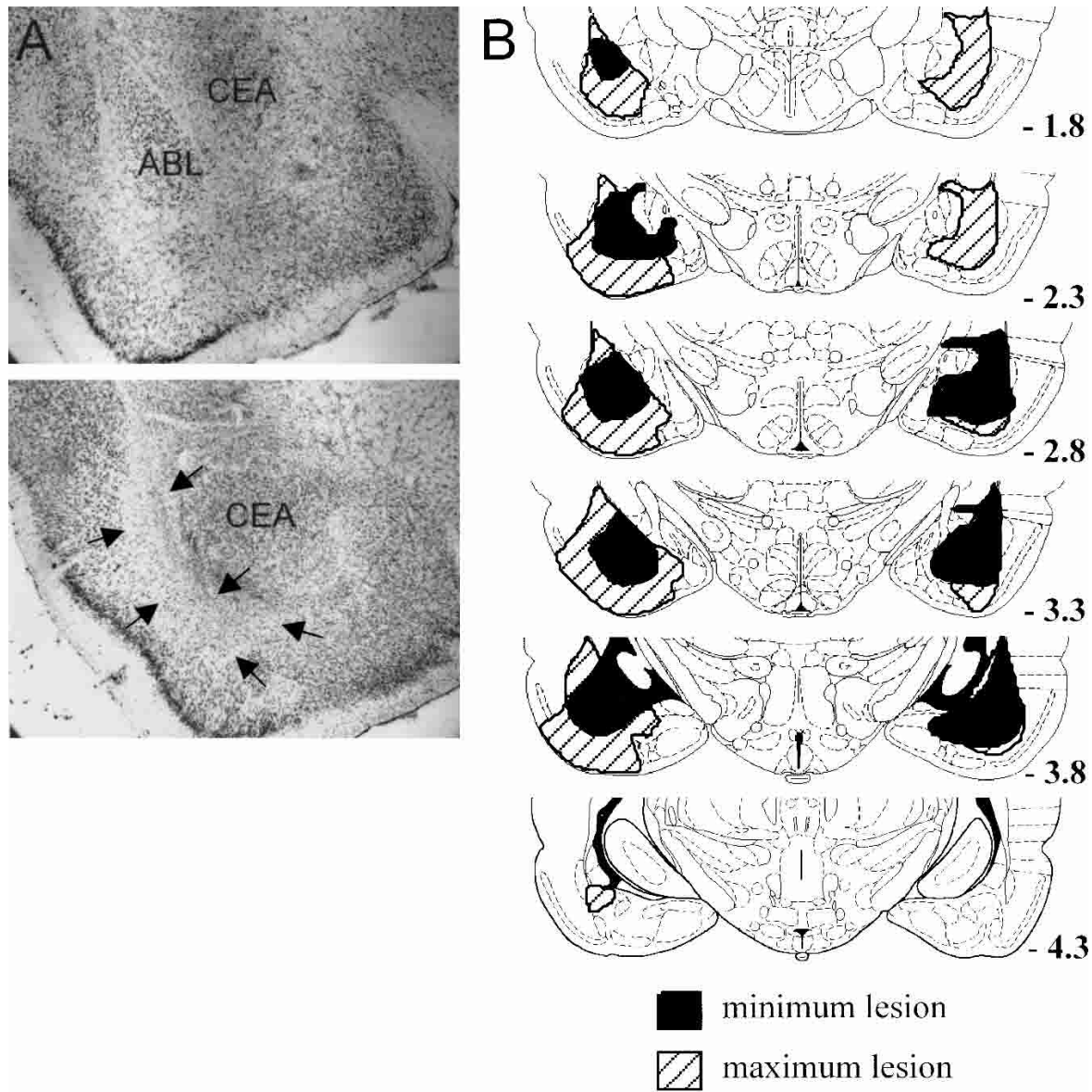

Figure 6 Photomicrograph and drawings showing a reconstruction of the region of damage in $A B L$ in lesioned subjects. (A) Photomicrograph of coronal sections taken through the amygdala in a control (top) and a lesioned (bottom) rat. The lesioned ABL tissue has undergone substantial shrinkage, causing the central nucleus (CEA) to be displaced laterally. (B) Drawings depict the largest (hatched areas) and smallest (black areas) lesions in each section from animals used in the experiment. Plates are adapted from the atlas of Paxinos and Watson (1997). Arrows denote lesion borders.

$\mathrm{X}$ reversal session) comparing the trials required to reach $50 \%$ performance after reversal showed no significant main effect or interaction with lesion. Again, there was a significant main effect of session $\left(\mathrm{F}_{1,15}=6.0, P<0.05\right)$, indicating that both lesioned and control rats required fewer trials to reach $50 \%$ performance on the second reversal than on the first one.

A final training session was conducted, in which the rats were required to demonstrate retention of the odor problem with the original contingencies. In agreement with the results of the analysis of the two reversals, indicating impaired performance by lesioned rats on the altered but not the original contingencies, there was no significant difference between groups in this retention test; controls met the behavioral criterion in $120+/-40$ trials, and rats with ABL lesions required $142+/-42$ trials.
2.3

\section{DISCUSSION}

The present report contains three main findings regarding the effects of $\mathrm{ABL}$ and $\mathrm{OFC}$ lesions on performance in a go, no-go odor discrimination task. First, both lesions abolished normal changes in response latencies during learning. Whereas intact rats in both experiments developed faster responses on positive trials and slower responses on negative trials, as they learned the response contingencies in each odor problem, rats with either OFC or ABLlesions failed to exhibit these latency changes. Second, this impairment occurred, with both lesions, in the absence of any impairments in choice behavior. Intact choice performance was observed despite the requirement that rats inhibit strong prepotent tendencies to respond at the fluid well, acquired through hundreds of shaping trials before discrimination training began. Third, the two lesions had distinct effects on reversal performance. Lesions of OFC produced the deficit in reversal learning often associated with damage to this region, whereas lesions of ABL produced a mild difficulty in acquiring and maintaining responding when the contingencies differed from the original learning.

\section{OFC and ABL-Lesioned Rats Fail to Show Changes in Response Latency During Acquisition of Go, No-Go Discriminations}

Latency to respond after sampling a cue provides a measure that is sensitive to the incentive value of an expected outcome in other paradigms (Holland and Straub 1979; Sage and Knowlton 2000; Watanabe et al. 2001). For example, rats trained to enter a food cup to obtain a food reward signaled by an auditory cue exhibit longer latencies to enter the food cup after the incentive value of the food is devalued through pairing with illness (Holland and Straub 1979). More recently, Sage and Knowlton (2000) reported that rats trained to complete trials to obtain food in a win-stay version of the radial arm maze also showed longer trial completion times (latencies) after devaluation of the food early in training. These data suggest that latency to respond for an

$$
\begin{array}{lllllllllllllll}
\text { www.learnmem.org } & & & & & & & & & &
\end{array}
$$




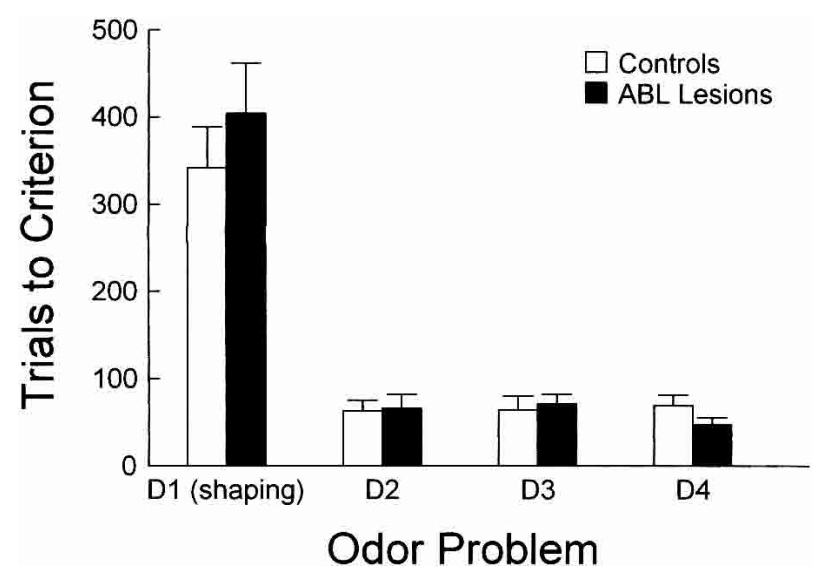

Figure 7 Acquisition of successive odor discrimination problems by $\mathrm{ABL}$ lesioned (black bars) and control (white bars) rats. Rate of acquisition of each odor discrimination problem (D1, D2, D3, D4) is represented as the trials it took for each rat to meet a criterion of 18 correct responses in a moving block of 20 trials. There was no effect of lesion on acquisition of any of the individual odor discriminations or on the improvement observed across successive problems.

outcome reflects knowledge of the incentive value of the associated outcome.

Experiments using similar methods of outcome devaluation have shown that $\mathrm{OFC}$ and $\mathrm{ABL}$ are both critical for modulating behavior to cues after changes in the incentive value of associated outcomes. For example, in a reinforcer devaluation paradigm, rats with neurotoxic lesions of either OFC or ABL fail to alter conditioned responding to a cue after the associated reward is devalued by pairing with illness (Hatfield et al. 1996; Gallagher et al. 1999). Similarly, monkeys with bilateral lesions of either structure or asymmetrical lesions that disconnect ABL and OFC have deficits in responding to cues after selective satiation on one of the associated rewards (Malkova et al. 1997; Baxter et al. 2000; Izquierdo and Murray 2000). These findings suggest that animals with lesions of ABL or OFC are unable to use predictive cues to access a representation of the associated outcome to guide or bias responding. Consistent with this hypothesis, amygdala inactivation immediately following exposure to a downshift in reward quantity in a runway task attenuates the normally observed increase in runway latency on the following day (Salinas et al. 1993).

In the current study, intact rats developed differences in their latencies to respond for reward following the positive and negative odors during learning. Rats with lesions of either OFC or ABL failed to exhibit this behavioral change. It is important to note that in the case of OFC-lesioned rats, the failure to modulate responding occurred on both positive and negative trials, indicating that the effect of these lesions on response latency cannot be explained by an inability to inhibit responding. Rather, these observations are consistent with research indicating that the latency to re- spond to cues can reflect the value of associated outcomes (Holland and Straub 1979; Sage and Knowlton 2000; Watanabe et al. 2001) and with reports that OFC and ABL are critical to learning such cue-outcome associations (Hatfield et al. 1996; Malkova et al. 1997; Gallagher et al. 1999; Baxter et al. 2000; Izquierdo and Murray 2000). Moreover, these results provide additional evidence that this function is impaired in lesioned animals during learning. It has not been clear from prior work using devaluation procedures (Hatfield et al. 1996; Gallagher et al. 1999) whether these structures are important for the formation of associations between cues and the incentive value of outcomes, or merely for updating these associations to reflect the new value of the outcome after devaluation. The current findings provide evidence in support of the former interpretation of the earlier findings.

The demonstration that $\mathrm{OFC}$ and $\mathrm{ABL}$ are both involved in the learning underlying normal discriminative performance is consistent with neural activity in ABL and $\mathrm{OFC}$ observed in this same training paradigm (Schoenbaum et al. $1998,1999)$. In those reports, both regions exhibited neural encoding that anticipated the expected outcomes when a response was made. Such activity developed in both OFC and $\mathrm{ABL}$ in the late phase of training, at the same time that the OFC/ABL-dependent latency changes were observed in the current report. In addition, selective activity developed in ABL during sampling of the odor cues in the late phase of training. Behavioral changes in the late phase of training may reflect the encoding properties of these neurons in $\mathrm{ABL}$ that link the cues to the outcomes.

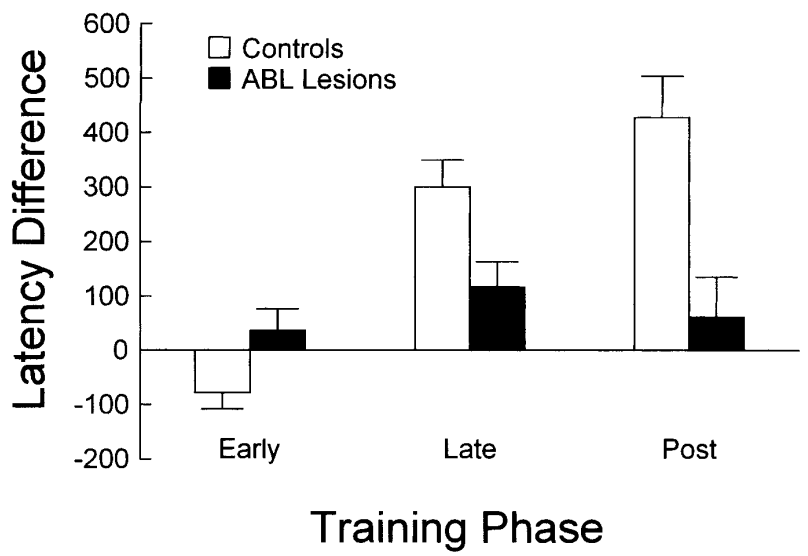

Figure 8 Difference in latency (milliseconds) to respond at the fluid well after the end of odor sampling for ABL lesioned (black bars) and control (white bars) rats. Difference was calculated as the average response latency on negative minus positive trials within each phase, averaged for the second (D2), third (D3), and fourth (D4) discrimination problems. No-go trials, in which the rat made no response for $3000 \mathrm{msec}$ were excluded from the analysis. ABLlesioned rats failed to develop the learning-related latency difference exhibited by control rats.

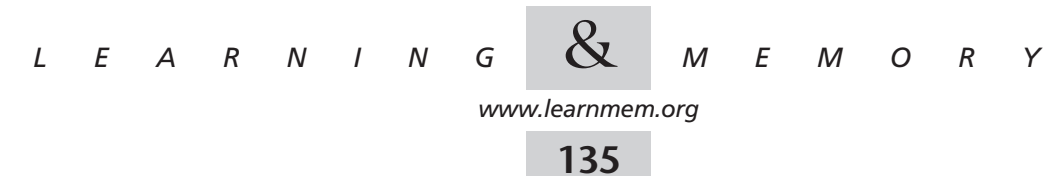




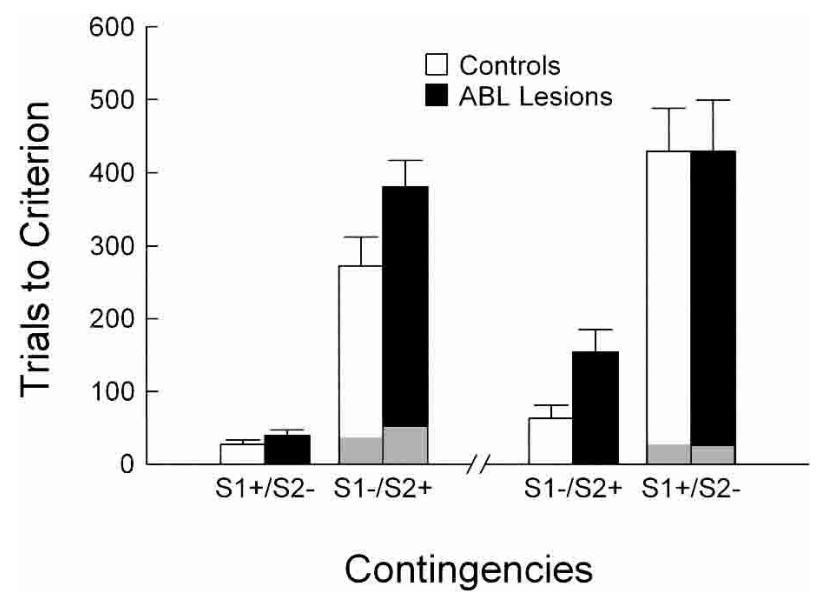

Figure 9 Choice performance across serial reversals of the final odor discrimination problem (D4) by ABL-lesioned (black bars) and control (white bars) rats. Performance is shown for both the retention and reversal phases of training, represented as the trials required for each rat to meet a criterion of 18 correct responses in a moving block of 20 trials. Gray areas on reversal days indicate the trials required to reach $50 \%$ performance as a measure of perseveration on the old contingencies. ABL-lesioned rats were impaired at acquiring and retaining the new contingencies (S1-/S2+), irrespective of whether the odor problem was presented with this set of contingencies in a reversal session or not. In contrast, ABL-lesioned rats performed normally in retaining and acquiring a reversal of the odor problem when it was presented with the original contingencies $(\mathrm{S} 1+/ \mathrm{S} 2-)$. There was no effect of lesion on the tendency to perseverate on reversal days.

\section{OFC and ABL-Lesioned Rats Are Not Impaired at Making Correct Choices During Acquisition of Go, No-Go Discriminations}

Despite the abnormal response latencies exhibited by both lesioned groups, there were no effects of lesions on choice performance during acquisition of the discrimination problems in the first phase of training. There are several implications of the intact choice performance and this dissociation in the two performance measures. First, the rats were able to inhibit go responses to the odor during this phase of training. This finding is particularly of interest with regard to the OFC-lesioned rats, as OFC lesions are closely associated with deficits in response inhibition. This result indicates that a simple inability to inhibit responding-without reference to the basis of that responding-cannot account for the effects of OFC lesions in this paradigm. Second, the successful acquisition of the discrimination problems indicates that the rats in the lesioned groups did not suffer from sensory deficits or nonspecific deficits in motivational function. As a result, the failure of lesioned rats to exhibit latency changes cannot be accounted for in terms of general motivational deficits or an inability to appreciate the hedonic properties of the sucrose and quinine outcomes. Finally, the dissociation between response latency changes and choice performance suggests that they may be supported by different associative mechanisms. In particular, choice performance under such simple circumstances could be mediated by mechanisms that do not directly reflect the incentive value of the outcomes (e.g., stimulusresponse associations). This speculation is consistent with other behavioral observations. For example, choice accuracy was not disrupted by reinforcer devaluation in the radial maze experiment described above, which demonstrated an effect of devaluation on latency measures only (Sage and Knowlton 2000), and other reports have found apparently normal performance after lesions that abolish control of behavior by stimulus-outcome associations (Hatfield et al. 1996; Blundell et al. 2001; Balleine and Dickinson 2000; Baxter et al. 2000). Notably, amygdala lesions that include ABL have no effect on quinine-motivated avoidance (choice) behavior (Cahill and McGaugh 1990). Together, these findings suggest that acquisition of odor discrimination problems is subserved by (at least) two associative mechanisms, only one of which was affected by lesions of $\mathrm{ABL}$ and $\mathrm{OFC}$.

\section{ABL-Lesioned Rats Do Not Exhibit the Reversal Deficit Observed After OFC Lesions}

Reversal learning impairments after OFC lesions are well documented (Teitelbaum 1964; Butter 1969; Jones and Mishkin 1972; Dias et al. 1997; Meunier et al. 1997; Ferry et al. 2000; Schoenbaum et al. 2002a). Our results confirm these earlier studies, demonstrating that neurotoxic lesions of OFC in rats result in impaired acquisition of reversals. In addition, these results parallel those in primates with OFC damage by showing intact choice performance on the initial discriminations, but impaired performance on the reversals (Rolls et al. 1994; Dias et al. 1997; Meunier et al. 1997). As in primates, rats with OFC lesions failed to reverse their responding as rapidly as intact controls, but did acquire the reversals after several hundred trials. In addition, the deficit was seen in reversal learning, irrespective of the contingencies; that is, whether the reversal involved a shift away from, or back to, the original contingencies in the odor problem. In contrast, rats with ABL lesions trained in the same reversal paradigm did not show a general deficit in acquiring reversals, but instead were only mildly impaired at acquiring the new contingencies that differed from initial learning.

It is unlikely that these deficits can be accounted for simply as a deficit in response inhibition, a function often ascribed to OFC. Although the rats had to learn to inhibit responding to the fluid well following the negative odor to acquire the discrimination problems, neither ABL or OFC lesions affected the rate of acquisition of these problems in the initial training phase. The ability to correctly inhibit responses on negative trials was intact, despite the rats having completed several hundred shaping trials, which strongly established this response tendency. In addition, the pattern of the reversal impairment exhibited by lesioned

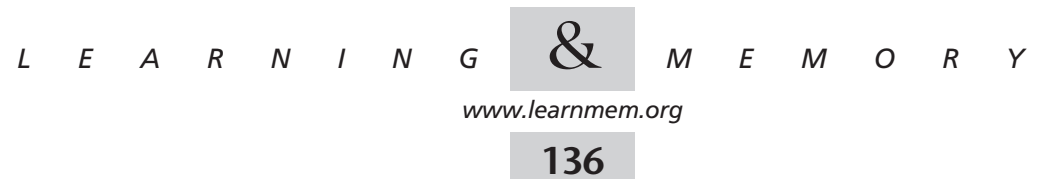


animals is inconsistent with a simple impairment in inhibiting prior response tendencies. Lesioned rats reached chance performance (i.e., go responses on every trial) after reversal at the same rate as controls. Thus, they were able to normally inhibit the pattern of go/no-go responding that was learned prior to the reversal. Although failure to inhibit responses may occur after OFC lesions in some situations, OFC lesions do not appear to cause a global deficit in response inhibition.

These findings are interesting in view of differences in neural encoding observed in these two regions during reversal learning in this same task (Schoenbaum et al. 1999). Distinct subsets of neurons in OFC develop representations of the unique odor-outcome pairings before and after reversal, such that a new population of OFC neurons becomes selective for odor cues during reversal. In contrast, neurons in ABL did not maintain distinct representations of the odoroutcome associations, but rather reversed their firing selectivity during odor sampling after the contingencies are reversed. These different populations of neurons in the two structures may subserve somewhat different roles in reversal learning, as indicated by the effects of damage to each structure. The property of conjunctive encoding by OFC neurons may be particularly critical to flexible behavioral adjustment, such that damage to OFC generally impairs shifts in choice behavior when contingencies vary (Rolls 1996). The mild impairment after ABL damage is consistent with our recent observation that $\mathrm{ABL}$ lesions in this paradigm diminish, but do not abolish, the development of selective firing in OFC to the novel odor-outcome contingencies after reversal (Schoenbaum et al. 2001). Thus, OFC may continue to mediate flexible responding without the information normally supplied by ABL.

The differential effect of ABL and OFC lesions on reversal learning also indicates that OFC performs a function during reversals that is somewhat independent of ABL. In addition to OFC's interconnections with ABL, a more general role in so-called executive function may depend on connections of OFC with many other brain regions such as piriform cortex, parietal areas, mediodorsal thalamus, and medial temporal lobe structures (Ongur and Price 2000; Schoenbaum et al. 2002b). Consistent with this view, neurons in OFC are responsive to many trial events in addition to those with specific motivational or incentive value (Schoenbaum and Eichenbaum 1995a; Schoenbaum et al. 1998; Lipton et al. 1999; Ramus and Eichenbaum 2000), and the encoding by OFC neurons often reflects the context and procedures specific to a particular task (Schoenbaum and Eichenbaum 1995b; Lipton et al. 1999; Schoenbaum et al. 1999; Ramus and Eichenbaum 2000; Wallis et al. 2001). Such data, combined with the present findings, suggest that OFC integrates incentive information via interconnections with ABL with other types of information to select appropriate behavioral responses (Schultz et al. 2000; Schoen- baum and Setlow 2001). The critical contribution of this function may be evident in reports that rats with OFC damage are impaired in making discriminative responses that require working memory for the incentive value of likely outcomes either across explicit delays (DeCoteau et al. 1997) or in situations in which such information must be implicitly maintained and manipulated to guide responding (Mobini et al. 2002).

\section{MATERIALS AND METHODS}

\section{Subjects}

All experimental procedures conformed to university and NIH guidelines. Forty-eight male Long-Evans rats (300-350 g), obtained from Charles River Laboratories served as subjects. Rats were housed individually on a 12-h light/12-h dark cycle (lights on at 8 AM) with ad libitum access to food and water except during testing. During testing, rats were given free access to water for $\sim 30 \mathrm{~min}$ per day after testing. All testing was performed during the light phase of the cycle.

\section{Surgery}

Rats were anesthetized with isoflurane and placed in a stereotaxic frame (Kopf Instruments) fitted with an isoflurane gas anesthesia system. A midline incision was made, the skin and periosteum retracted, and holes drilled through the skull over the lesion sites. Lesions were made using intracerebral infusions of $N$-methyl-D-aspartic acid (NMDA) in a phosphate buffer vehicle. Infusions of phosphate buffer vehicle alone were used to make control lesions.

For OFC lesions (which were intended to include orbital and the dorsal and ventral agranular insular cortices), infusions of $0.1 \mu \mathrm{L}$ of either NMDA $(20 \mu \mathrm{g} / \mu \mathrm{L})$ or vehicle alone were made at four separate sites in each hemisphere, using a glass micropipette attached by a length of plastic tubing to a picospritzer (General Valve Corporation). One set of infusions was made at $4.0 \mathrm{~mm}$ anterior to bregma, and at 2.2 and $3.7 \mathrm{~mm}$ lateral to the midline, at a depth of $4.2 \mathrm{~mm}$ ventral to the skull surface. A second set was made at $3.0 \mathrm{~mm}$ anterior to bregma, 3.2 and $4.2 \mathrm{~mm}$ lateral to the midline, and $5.2 \mathrm{~mm}$ ventral to the skull surface. Sixteen rats received NMDA infusions, and eight rats received vehicle infusions. For ABL lesions (which were intended to include the lateral, basal, and accessory basal nuclei), infusions of NMDA $(12.5 \mu \mathrm{g} / \mu \mathrm{L})$ or vehicle alone were made at two sites in each hemisphere, using a 30-gauge cannula attached by a length of plastic tubing to a microsyringe (Hamilton) mounted on a syringe pump (Sage Instruments). Both sites were located at $2.8 \mathrm{~mm}$ posterior to bregma, $5.0 \mathrm{~mm}$ lateral to the midline. At these coordinates, we infused $0.2 \mu \mathrm{L}$ NMDA or vehicle at $8.7 \mathrm{~mm}$ ventral to the skull surface, and $0.1 \mu \mathrm{L}$ NMDA or vehicle at $8.4 \mathrm{~mm}$ ventral to the skull surface. Fourteen rats received NMDA infusions, and ten rats received vehicle infusions.

Following infusions, the pipette or cannula was left in place for $3 \mathrm{~min}$ at each site to allow for diffusion. Following surgery, the incision was closed with wound clips and antibiotic ointment was applied to the wound site. Rats were monitored during recovery from anesthesia and on subsequent days, for behavioral disturbances and signs of infection.

\section{Apparatus}

Behavioral testing was conducted using a set of four identical chambers. Each chamber was constructed of aluminum and measured

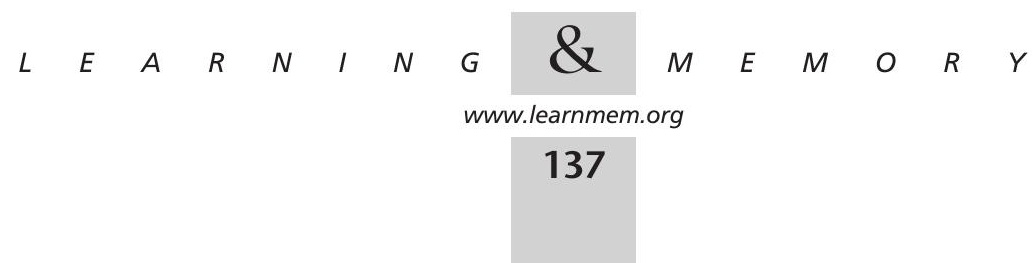


$\sim 45 \mathrm{~cm}$ on a side, but with sloping walls narrowing to an area $30 \mathrm{~cm} \times 30 \mathrm{~cm}$ at the floor. An exhaust fan was located on the upper back wall, and the front wall was hinged to open outward and provide access to the interior. Two panel lights were located on the right wall of the chamber. The test chambers were located in a small room $(3 \mathrm{~m} \times 3 \mathrm{~m})$, the door to which remained closed during behavioral sessions. Two speakers located in the corners of the room broadcast output from a white noise generator to mask extraneous noise.

Each chamber was connected to a Pentium II $266 \mathrm{MHz}$ computer for behavioral control and data acquisition. Sessions were conducted using a program written in C++ and running in DOS. Registers located on a DT2817 I/O board (Data Translation) were used to control and detect events. Events (animal and computer initiated) were time stamped using values from a CIO-DIO-CTR3 clock timer board (Computer Boards), capable of microsecond resolution. These data were saved for later analysis.

Odors were selected from a set of compounds obtained from International Flavors and Fragrances, which were classified subjectively into categories. Discrimination problems consisted of odors from different categories (fruity, spicy, herbal, etc.), and categories did not repeat in sequentially presented discriminations. These odor compounds were diluted 1:20 in propylene glycol. The set of diluted odors used in the discrimination problems in this experiment were isolated on a removable cartridge connected to a system of solenoids and flowmeters to allow each odor to be individually delivered to the training chamber. All tubing and valves associated with an odor were dedicated to that odor to prevent any crosscontamination between cues, and each training chamber had an identical set of odor cues (Schoenbaum 2001).

Odors were presented at an odor delivery port located in a polycarbonate panel (Fig. 1A) bolted into an opening in the right wall of each operant box below the panel lights. The odor sampling port consisted of a $2.5-\mathrm{cm}$ diameter opening. A photobeam across the opening registered nosepokes into the port. Behind this port was a small hemicylinder in which odorized air streams could be presented when a rat nosepoked at the odor port. Odors were delivered through tubing connected to the base of the hemicylinder behind the sampling port

Before each trial, an odor was selected for delivery by opening a solenoid valve that allowed a clean air stream to pass over one of the odor solutions on the removable cartridge. The odorized air stream at $1.5 \mathrm{~L} / \mathrm{min}$ was brought to a vacuum dump behind the odor port. This vacuum drew at $2.0 \mathrm{~L} / \mathrm{min}$ and was also attached by a 1-cm line to the hemicylinder behind the odor port, resulting in a negative flow of $0.5 \mathrm{~L} / \mathrm{min}$ out of the hemicylinder at all times except during odor delivery. Odor delivery was initiated by closing the vacuum upon detection of a nosepoke at the odor port, thereby causing the odorized air stream to be diverted into the hemicylinder behind the port with an onset latency of $\sim 25 \mathrm{msec}$. Odor delivery was terminated by opening the vacuum when the rat left the odor port. During odor presentation, a second vacuum line drawing at $2.0 \mathrm{~L} / \mathrm{min}$ from the top of the hemicylinder prevented the odor from entering the training chamber.

Fluids were delivered to a depression located in a ledge just below the odor sampling port (Fig. 1A). Responses at the fluid well were detected by a photobeam passing parallel to the ledge $\sim 1 \mathrm{~mm}$ above the well depression. The well depression was tapped with a single line at the bottom. This central line opened into four lines concealed deeper in the ledge. Two of these lines were used to deliver sucrose and quinine solutions. A third line was used to deliver water to clean the well between trials, and the fourth line was used as a vacuum-assisted drain line. Solenoid valves controlled the delivery of each fluid and the operation of the drain.

\section{Behavioral Testing}

Prior to odor discrimination training, all rats in the current study received training in a food-motivated Pavlovian second-order conditioning task by use of visual and auditory-conditioned stimuli. This training occurred in a separate apparatus in a location different from that used in the present experiment, by use of different cues and reinforcers than the current paradigm. Approximately 3 wk elapsed between the completion of this Pavlovian training paradigm and the start of odor discrimination training. During this time, the rats remained in their home cages and received periodic handling and ad lib food and water.

Before the start of odor discrimination training, rats were shaped to nosepoke at the odor port to receive a water reward in the fluid well. The rats were gradually shaped to hold their snout in the odor port for a period of $250 \mathrm{msec}$ before odor delivery and 500 msec after odor delivery and to make a response to the fluid well within $3000 \mathrm{msec}$ to receive reward. Once shaped to this procedure, the first phase of odor discrimination training was begun.

During odor discrimination training, the rats were presented with a series of odor problems. Each odor discrimination problem consisted of two odors. One odor signaled a positive outcome, indicating that a response at the fluid well would result in delivery of a $5 \%$ sucrose solution. The other odor signaled a negative outcome, indicating that the same response would result in delivery of a $0.02 \mathrm{M}$ quinine solution. Trials were signaled to the rat by illumination of the panel lights inside the box. When these lights were on, nosepoke into the odor port (Fig. 1B) resulted in delivery of the preselected odor cue. The rat terminated odor sampling by leaving the odor port. The rat then had $3 \mathrm{sec}$ to make a go response at the fluid well (Fig. 1B). If a response was detected, then fluid was delivered to the well. After a response, fluid remained in the well and the panel lights remained on until the rat left the fluid well, then the fluid was removed by activating the drain line, and the lights were extinguished to end the trial. If the rat did not respond at the fluid well within $3 \mathrm{sec}$ of exiting the odor port, the trial was counted as a no-go (Fig. 1B), and the panel lights were extinguished. Typically, rats began each new discrimination problem by responding to both odors, and then learned to withhold responding on negative trials in order to avoid the aversive quinine (Fig. 1B). Intertrial intervals were $4 \mathrm{sec}$ after correct responses and $9 \mathrm{sec}$ after incorrect responses. During the intertrial intervals, the fluid well was flushed with water twice, and an odor was selected for presentation on the following trial.

Odor discrimination training was divided into two phases. In the first phase, rats were required to learn a series of four 2-odor discrimination problems (D1-D4). Note that the first odor problem (D1) served as a shaping problem in which the rats were introduced to odors and to the sucrose and quinine reinforcers for the first time in the context of the task. Training continued on this and each of the subsequent nonshaping odor problems until the rat met a criterion of 18 correct responses in a moving block of 20 trials. Rats were run for $\sim 1 \mathrm{~h}$ each day, or until this criterion was achieved. When an odor problem was acquired, training was begun on the next problem in the series in the next day's session.

Once the first four odor problems (D1-D4) were acquired, the rats began the second phase of training. In the second training phase, the rats were required to learn a series of reversals, in which the contingencies signaled by the odor cues in a single discrimina-

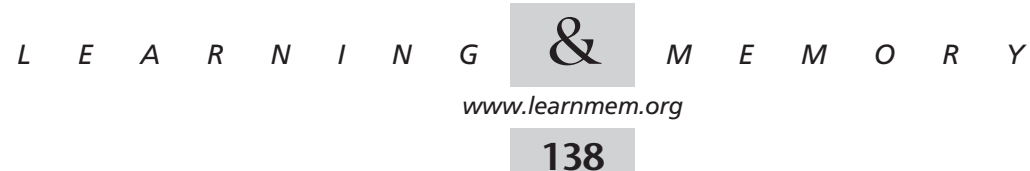


tion problem were altered. This phase began with presentation of the most recently acquired odor problem (D4) by use of the same contingencies that were used in initial training $(\mathrm{S} 1+/ \mathrm{S} 2-)$. Once the rats demonstrated retention of this odor problem with the original contingencies by meeting a behavioral criterion of 18 correct responses in a moving block of 20 trials, the response contingencies were reversed, provided the rat had maintained $80 \%$ performance over a block of 60 trials preceding reversal. This secondary performance requirement ensured that all rats were equally proficient on the odor problem before reversal. Training on the reversed problem $(\mathrm{S} 1-/ \mathrm{S} 2+)$ continued until the behavioral criterion was met again.

After this first reversal was completed, the contingencies for the same odor cues were reversed a second time in the same manner. The reversed discrimination problem (S1-/S2+) was presented, and the rats were required to demonstrate retention of this problem with these contingencies by achieving the behavioral criterion of 18 correct responses in a moving block of 20 trials. When these criteria were met, the problem was immediately reversed back to the original contingencies $(\mathrm{S} 1+/ \mathrm{S} 2-)$, provided the rat had maintained $80 \%$ performance over a block of 60 trials preceding reversal. Training on this re-reversal continued until each rat met the behavioral criterion again

\section{Histology}

After completion of all behavioral testing, rats were given an overdose of pentobarbital $(100 \mathrm{mg} / \mathrm{kg})$ and perfused intracardially with $0.9 \%$ saline followed by $4 \%$ formaldehyde. Brains were removed and stored in $4 \%$ formaldehyde for $24 \mathrm{~h}$, followed by $30 \%$ sucrose in $4 \%$ formaldehyde until slicing. The brains were sliced on a freezing microtome, and $40-\mu \mathrm{m}$ coronal sections were collected through OFC in the first study and ABL in the second study. These sections were mounted on glass slides, stained with thionin, and coverslipped with Permount. Lesion placements were verified under a light microscope and drawn onto plates adapted from the atlas of Paxinos and Watson (1997).

\section{Data Analysis}

Acquisition on each discrimination problem in the first phase of the study was evaluated by calculating the trials required to reach the behavioral criterion for each animal (18/20 correct). These data were analyzed by ANOVA with repeated measures (lesion X odor problem). A response latency measure obtained during the acquisition of the three nonshaping discrimination problems (D2-D4) was also analyzed. Latency to respond at the fluid well after odor sampling was calculated for positive and negative go trials. For the analysis of this behavioral measure, trials that occurred before criterion were divided into an early and late phase of acquisition, the border between which was defined by the occurrence of the sixth error in the session. The difference in latency on positive and negative trials was analyzed by ANOVA with repeated measures (lesion $\mathrm{X}$ odor problem $\mathrm{X}$ training phase). Performance in the reversal phase was evaluated by comparing the trials required to meet the behavioral criterion when retaining and reversing the D4 odor problem with either the original or the altered contingencies. These data were analyzed by ANOVA with repeated measures (lesion $\mathrm{X}$ contingency $\mathrm{X}$ reversal). Statistics were computed using the ANOVA/MANOVA module in Statistica (Statsoft), and individual comparisons were made using contrasts $(P<0.05)$.

\section{ACKNOWLEDGMENTS}

This work was supported by K08-AG00882 to G.S. from the NIA and by F32-MH12699 to B.S., and R01-MH53667 to M.G. from the NIMH.

The publication costs of this article were defrayed in part by payment of page charges. This article must therefore be hereby marked "advertisement" in accordance with 18 USC section 1734 solely to indicate this fact.

\section{REFERENCES}

Balleine, B.W. and Dickinson, A. 2000. The effect of lesions of the insular cortex on instrumental conditioning: Evidence for a role in incentive memory. J. Neurosci. 20: 8954-8964.

Baxter, M.G., Parker, A., Lindner, C.C.C., Izquierdo, A.D., and Murray, E.A 2000. Control of response selection by reinforcer value requires interaction of amygdala and orbitofrontal cortex. J. Neurosci. 20: 4311-4319.

Bechara, A., Damasio, H., Tranel, D., and Damasio, A.R. 1997. Deciding advantageously before knowing the advantageous strategy. Science 275: 1293-1294.

Bechara, A., Damasio, H., Damasio, A.R., and Lee, G.P. 1999. Different contributions of the human amygdala and ventromedial prefrontal cortex to decision-making. J. Neurosci. 19: 5473-5481.

Blundell, P., Hall, G., and Killcross, S. 2001. Lesions of the basolateral amygdala disrupt selective aspects of reinforcer representation in rats. J. Neurosci. 21: 9018-9026.

Brown, S. and Schafer, E.A. 1888. An investigation into the functions of the occipital and temporal lobes of the monkey's brain. Phil. Trans. Royal Soc. London B 179: 303-327.

Butter, C.M. 1969. Perseveration and extinction in discrimination reversal tasks following selective frontal ablations in Macaca mulatta. Physiol. Behav. 4: 163-171.

Cahill, L. and McGaugh, J.L. 1990. Amygdaloid complex lesions differentially affect retention of tasks using appetitive and aversive reinforcement. Behav. Neurosci. 104: 532-543

Carmichael, S.T. and Price, J.L. 1995. Limbic connections of the orbital and medial prefrontal cortex in macaque monkeys. J. Comp. Neurol. 363: 615-641.

Cinelli, A.R., Moyano-Ferreyra, H., and Barragan, E. 1985. Reciprocal functional connections of the olfactory bulbs and other olfactory related areas with the prefrontal cortex. Brain Res. Bull. 19: 651-661.

Davis, M. 1992. The role of the amygdala in conditioned fear. In: The amygdala: Neurological aspects of emotion, memory, and mental dysfunction. (ed. J.P. Aggleton), pp. 255-306. Wiley, Chichester, UK.

DeCoteau, W.E., Kesner, R.P., and Williams, J.M. 1997. Short-term memory for food reward magnitude: The role of the prefrontal cortex. Behav. Brain Res. 88: 239-249.

Dias, R., Robbins, T.W., and Roberts, A.C. 1997. Dissociable forms of inhibitory control within prefrontal cortex with an analog of the Wisconsin card sort test: Restriction to novel situations and independence from "on-line" processing. J. Neurosci. 17: 9285-9297.

Everitt, B.J., Cardinal, R.N., Hall, J., Parkinson, J.A., and Robbins, T.W. 2000. Differential involvement of amygdala subsystems in appetitive conditioning and drug addiction. In: The amygdala: A functional analysis. (ed. J.P. Aggleton), pp. 353-390. Oxford University Press, New York, NY

Ferry, A.T., Lu, X.C., and Price, J.L. 2000. Effects of excitotoxic lesions in the ventral striatopallidal-thalmocortical pathway on odor reversal learning: Inability to extinguish an incorrect response. Exper. Brain Res. 131: 320-335

Gallagher, M., McMahan, R.W., and Schoenbaum, G. 1999. Orbitofrontal cortex and representation of incentive value in associative learning. J. Neurosci. 19: 6610-6614.

Harlow, J.M. 1868. Recovery after passage of an iron bar through the head. Publications of the Massachusetts Medical Society. 2: 329-346.

Hatfield, T., Han, J.S., Conley, M., Gallagher, M., and Holland, P. 1996. Neurotoxic lesions of basolateral, but not central, amygdala interfere

\section{$\begin{array}{lllllllllllllllll}L & E & A & R & N & I & N & G & \& & M & E & M & O & R & Y\end{array}$}


with Pavlovian second-order conditioning and reinforcer devaluation effects. J. Neurosci. 16: 5256-5265.

Holland, P.C. and Straub, J.J. 1979. Differential effects of two ways of devaluing the unconditioned stimulus after Pavlovian appetitive conditioning. J. Exper. Psychol.: Anim. Behav. Proc. 5: 65-78.

Izquierdo, A.D. and Murray, E.A. 2000. Bilateral orbital prefrontal cortex lesions disrupt reinforcer devaluation effects in rhesus monkeys. Soc Neurosci. Abstr. 26: 978.

Jones, B. and Mishkin, M. 1972. Limbic lesions and the problem of stimulus-reinforcement associations. Exper. Neurol. 36: 362-377.

Killcross, S., Robbins, T.W., and Everitt, B.J. 1997. Different types of fear conditioned behavior mediated by separate nuclei within amygdala. Nature 388: 377-380

Kita, H. and Kitai, S.T. 1990. Amygdaloid projections to the frontal cortex and the striatum in the rat. J. Comp. Neurol. 298: 40-49.

Kluver, H. and Bucy, P.C. 1939. Preliminary analysis of the temporal lobes in monkeys. Arch. Neurol. Psych. 42: 979-1000.

Kosar, E., Grill, H.J., and Norgren, R. 1986. Gustatory cortex in the rat. I. Physiological properties and cytoarchitecture. Brain Res. 379: 329-341.

Krettek, J.E. and Price, J.L. 1977. Projections from the amygdaloid complex to the cerebral cortex and thalamus in the rat and cat. J. Comp. Neurol. 172: 225-254

Krushel, L.A. and Van Der Kooy, D. 1988. Visceral cortex: Integration of the mucosal senses with limbic information in the rat agranular insular cortex. J. Comp. Neurol. 270: 39-54.

LeDoux, J.E. 1996. The emotional brain. Simon and Schuster, New York, NY.

Lipton, P.A., Alvarez, P., and Eichenbaum, H. 1999. Crossmodal associative memory representations in rodent orbitofrontal cortex. Neuron 22: 349-359.

Malkova, L., Gaffan, D., and Murray, E.A. 1997. Excitotoxic lesions of the amygdala fail to produce impairment in visual learning for auditory secondary reinforcement but interfere with reinforcer devaluation effects in rhesus monkeys. J. Neurosci. 17: 6011-6020.

Meunier, M., Bachevalier, J., and Mishkin, M. 1997. Effects of orbital frontal and anterior cingulate lesions on object and spatial memory in rhesus monkeys. Neuropsychologia 35: 999-1015.

Mobini, S., Body, S., Ho, M.Y., Bradshaw, C.M., Szabadi, E., Deakin, J.F., and Anderson, I.M. 2002. Effects of lesions of the orbitofrontal cortex on sensitivity to delayed and probabilistic reinforcement Psychopharmacology 160: 290-298.

Ongur, D. and Price, J.L. 2000. The organization of networks within the orbital and medial prefrontal cortex of rats, monkeys and humans. Cerebral Cortex 10: 206-219.

Paxinos, G. and Watson, C. 1997. The rat brain in stereotaxic coordinates. Academic Press, New York, NY.

Price, J.L., Carmichael, S.T., Carnes, K.M., Clugnet, M.C., Kuroda, M., Ray, J.P. 1991. Olfactory input to the prefrontal cortex. In: Olfaction: A model system for computational neuroscience. (ed. J. Davis and $\mathrm{H}$. Eichenbaum), pp. 101-120. MIT Press, Cambridge MA.

Ramus, S.J. and Eichenbaum, H. 2000. Neural correlates of olfactory recognition memory in the rat orbitofrontal cortex. J. Neurosci. 20: 8199-8208

Rolls, E.T. 1996. The orbitofrontal cortex. Phil. Trans. Royal Soc. London B 351: 1433-1443.

Rolls, E.T., Hornak, J., Wade, D., and McGrath, J. 1994. Emotion-related learning in patients with social and emotional changes associated with frontal lobe damage. J. Neurol. Neuros. Psych. 57: 1518-1524.

Sage, J.R. and Knowlton, B.J. 2000. Effects of US devaluation on win-stay and win-shift radial maze performance in rats. Behav. Neurosci. 114: 295-306.

Salinas, J.A., Packard, M.G., and McGaugh, J.L. 1993. Amygdala modulates memory for changes in reward magnitude: Reversible post-training inactivation with lidocaine attenuates the response to a reduction in reward. Behav. Brain Res. 59: 153-159.

Saper, C.B. 1982. Convergence of autonomic and limbic connections in the insular cortex of the rat. J. Comp. Neurol. 210: 163-173

Schoenbaum, G. 2001. Olfactory learning and the neurophysiological study of rat prefrontal function. In CRC series: Methods in chemosensory research. (ed. M.A.L. Nicolelis and S.A. Simon), pp. 371-427. CRC Press, Boca Raton, FL.

Schoenbaum, G. and Eichenbaum, H. 1995a. Information coding in the rodent prefrontal cortex. I. Single-neuron activity in orbitofrontal cortex compared with that in pyriform cortex. J. Neurophysiol. 74: 733-750.

. 1995b. Information coding in the rodent prefrontal cortex. II. Ensemble activity in orbitofrontal cortex. J. Neurophysiol. 74: 751-762

Schoenbaum, G. and Setlow, B. 2001. Integrating orbitofrontal cortex into prefrontal theory: Common processing themes across species and subdivision. Learn. Mem. 8: 134-147.

Schoenbaum, G., Chiba, A.A., and Gallagher, M. 1998. Orbitofrontal cortex and basolateral amygdala encode expected outcomes during learning. Nature Neurosci. 1: 155-159.

. 1999. Neural encoding in orbitofrontal cortex and basolateral amygdala during olfactory discrimination learning. J. Neurosci. 19: $1876-1884$

. 2000. Rapid changes in functional connectivity in orbitofrontal cortex and basolateral amygdala during learning and reversal. J. Neurosci. 20: 5179-5189.

Schoenbaum, G., Setlow, B., Saddoris, M.P., and Gallagher, M. 2001. Basolateral amygdala lesions disrupt neural correlates of incentive value in orbitofrontal cortex. Soc. Neurosci. Abstr. 27: 421.6.

Schoenbaum, G., Nugent, S., Saddoris, M.P., and Setlow, B. 2002a Orbitofrontal lesions in rats impair reversal but not acquisition of go, no-go odor discriminations. Neuroreport 13: 885-890.

Schoenbaum, G., Setlow, B., and Gallagher, M. 2002b. Orbitofrontal cortex: Modeling prefrontal function in rats. In The neuropsychology of memory. (ed. L. Squire and D. Schacter), pp. 463-477. Guilford Press, New York, NY.

Schultz, W., Tremblay, L., and Hollerman, J.R. 2000. Reward processing in primate orbitofrontal cortex and basal ganglia. Cerebral Cortex 10: $272-283$.

Shi, C.J. and Cassell, M.D. 1998. Cortical, thalamic, and amygdaloid connections of the anterior and posterior insular cortices. J. Comp Neurol. 399: 440-468.

Swanson, L.W. 1992. Brain maps: Structure of the rat brain. Elsevier, New York, NY

Teitelbaum, H. 1964. A comparison of effects of orbitofrontal and hippocampal lesions upon discrimination learning and reversal in the cat. Exper. Neurol. 9: 452-462.

Tremblay, L. and Schultz, W. 1999. Relative reward preference in primate orbitofrontal cortex. Nature 398: 704-708

Wallis, J.D., Anderson, K.C., and Miller, E.K. 2001. Single neurons in prefrontal cortex encode abstract rules. Nature 411: 953-956.

Watanabe, M., Cromwell, H.C., Tremblay, L., Hollerman, J.R., Hikosaka, K. and Schultz, W. 2001. Behavioral reactions reflecting differential reward expectations in monkeys. Exper. Brain Res. 140: 511-518.

Weiskrantz, L. 1956. Behavioral changes associated with ablations of the amygdaloid complex in monkeys. J. Comp. Physiol. Psychol. 9: 381-391.

Received August 27, 2002; accepted in revised form December 5, 2002.

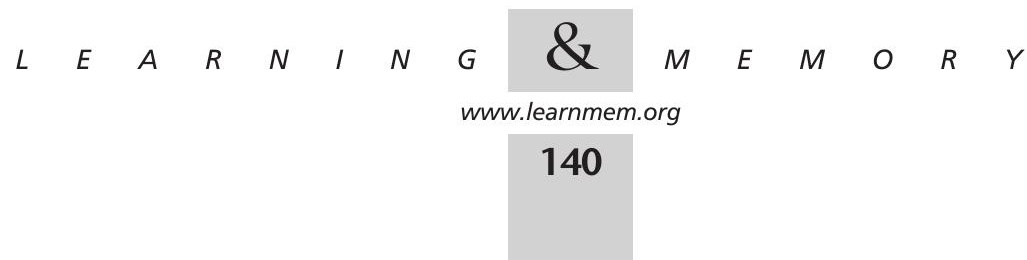




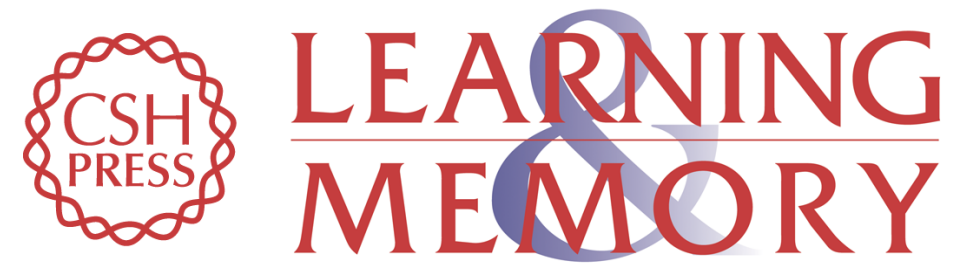

\section{Lesions of Orbitofrontal Cortex and Basolateral Amygdala Complex Disrupt Acquisition of Odor-Guided Discriminations and Reversals}

Geoffrey Schoenbaum, Barry Setlow, Summer L. Nugent, et al.

Learn. Mem. 2003, 10:

Access the most recent version at doi:10.1101/lm.55203

References This article cites 50 articles, 14 of which can be accessed free at:

http://learnmem.cshlp.org/content/10/2/129.full.html\#ref-list-1

License

Email Alerting Receive free email alerts when new articles cite this article - sign up in the box at the Service top right corner of the article or click here. 